\title{
BASES MOLECULARES DE LA ERECCIÓN
}

Manuel Mas.

Departamento de Fisiología y Centro de Estudios Sexológicos (CESEX).

Facultad de Medicina. Universidad de La Laguna. Tenerife. España.

Resumen.- Los estados fisiológicos de flacidez o de erección del pene resultan de contracción o la relajación, respectivamente, de las células musculares lisas del cuerpo cavernoso (CSMCs). Son determinados por la interacción de diversas vías de señalización molecular inter- e intracelulares.

En el estado más frecuente, de flacidez, predomina una actividad tónica de la inervación simpática, con liberación de noradrenalina (NA) y otros mensajeros que generan señales contráctiles en el músculo liso cavernoso, con la cooperación probable de otras procedentes del endotelio. Todas ellas activan receptores de membrana

\section{CORRESPONDENCIA}

Manuel Mas

Universidad de La Laguna

Facultad de Medicina

Departamento de Fisiología

38071 La Laguna. Tenerife (España)

mmas@ull.es en las CSMCs que generan los mensajeros intracelulares inositol trifosfato (IP3) y diacilglicerol (DAG). El resultado es un aumento transitorio de la concentración intracitosólica de calcio ([ $\left.\mathrm{Ca}^{+2}\right]$ i) que inicia la respuesta contráctil así como la activación de un mecanismo de "sensibilización al calcio" operado por la vía RhoA/ ROCK que la mantiene. La sobre-expresión de dicho mecanismo parece contribuir a la patogenia de diversos trastornos vasculares como la hipertensión, el vasoespasmo o la disfunción eréctil.

La estimulación sexual hace que los nervios erectores liberen óxido nítrico (NO), que inicia la respuesta eréctil. Los nervios erectores liberan también acetilcolina que activa la producción, más sotenida, de NO por el endotelio, que se suma al de origen neural. La entrada de NO por difusión a las células musculares lisas genera en ellas guanosín monofosfato cíclico (cGMP) que induce una serie de reacciones que llevan a la disminución de $\left[\mathrm{Ca}^{+2}\right]$ i y la inactivación del mecanismo de sensibilización al calcio, lo que relaja las CSMCs. A este sistema principal de señalización erectogénica se añade, con efectos similares, el del adenosín monofosfato cíclo (cAMP), activado por diversos mensajeros intercelulares de origen neural y paracrino, como la prostaglandina E (PGE). Diversas fosfodiesterases (PDEs) inactivan dichos nucleótidos cíclicos, limitando su acción erectogénica. La inhibición farmacológica, particularmente de la PDE5 (especifica del cGMP), facilita considerablemente la respuesta eréctil. Hay mecanismos de intercomunicación entre ambas vías de señalización erectogénica (cGMP y CAMP) que pueden aprovecharse en la terapia farmacológica de la disfunción eréctil.

Palabras clave: Cuerpo cavernoso. Músculo liso. Oxido nítrico. Nucleótidos cíclicos. Fosfodiesterasas. Sensibilización al calcio. Disfunción eréctil. 
Summary.- The penis physiological states of flaccidity or erection, result from the contraction or relaxation, respec-tively, of smooth muscle cells in the corpora cavernosa (CSMCs). They result from the interaction of various inter-and intracellular molecular signaling pathways.

During the more usual state of flaccidity seems to pre-dominate a tonic sympathetic activity, releasing nora-drenaline (NA) and other agonists that generate con-tractile signals in the CSMCs, with the likely cooperation of endothelium-derived messengers. Through activation of membrane receptors in the CSMCs they raise the intracellular messengers inositol triphosphate (IP3) and diacylglycerol (DAG). This results in a transient increase in cytosolic calcium concentration [Ca2+]i that starts the contractile response which is further sustained by the parallel agonist-induced activation of a "calcium sensitizing" mechanism involving the RhoA/Rho-kinase pathway. Overexpression of the latter might contribute to several vascular disorders as hypertension, vasospasm or erectile dysfunction.

On sexual stimulation the cavernous nerves release nitric oxide (NO) that starts the erectile response. They also release acetylcholine that stimulates the endothelium to generate a more sustained release of NO. NO diffuses into CSMCs and increases their intracellular levels of cyclic guanosin monophosphate (cGMP) which decrea-ses [Ca2+]i and deactivates the calcium sensitizing mechanism, thus relaxing CSMCs. This main physiological pathway for CSMCs relaxation is helped by the cyclic adenosin monophosphate (cAMP) pathway activated by various intercellular messengers from neural or paracrine sources, including prostaglandins E (PGE). Different phosphodiesterase enzymes (PDEs) inactivate the cyclic nucleotides thereby limiting their erectogenic action. Indeed the pharmacological inhibition of PDEs, especially the CGMP-specific PDE5, greatly enhances the erectile responses. There are cross-talk mechanisms between the CGMP and CAMP signaling pathways that offer additional possibilities for the pharmacotherapy of erectile dysfunction.

Keywords: Corpus cavernosum. Smooth muscle. Nitric Oxide. Cyclic nucleotides. Phosphodiesterases. Calcium sensitization. Erectile dysfunction.

\section{INTRODUCCIÓN}

La erección y detumescencia peneanas son el resultado de la relajación y contracción, respectivamente, del músculo liso que forma parte de las paredes de las arterias cavernosas y sus ramas, las arterias helicinas, así como de las trabéculas de los sinusoides cavernosos. El presente artículo trata de resumir los principales mecanismos reguladores de dichos fenómenos (para revisiones más amplias véanse refs $1-5$ ). Aunque hay algunas diferencias en la regulación del músculo liso trabecular y el arterial (2), en aras de una mayor claridad aquí se tratará conjuntamente como "músculo liso cavernoso".

\section{Sinopsis del aparato contráctil del Músculo Liso y su regulación}

Como en todos los músculos, estriados y lisos, el aparato contráctil del músculo liso cavernoso consta esencialmente de dos tipos de miofilamentos: finos y gruesos, que se interdigitan con grados diversos de superposición; el grado de entrecruzamiento de unos con otros determina el de la contracción o la relajación musculares (véase ref. 6 para una descripción general de la estructura y funcionamiento de las células musculares lisas).

Los filamentos finos, los más largos, están constituidos esencialmente por múltiples unidades de la proteína globular actina, que se engarzan a modo de "cuentas de rosario" en dos hileras entrelazadas que conforman el filamento. Además contienen menores cantidades de otras proteínas reguladoras como tropomiosina, análoga a la del músculo estriado, y otras específicas como caldesmona (proteína ligadora de calmodulina) y calponina (proteína inhibidora de la interacción actina-miosina). Los filamentos finos se insertan por uno de sus extremos en los llamados cuerpos densos, formaciones presentes en el citoplasma y la membrana celular (formados por diversas proteínas estructurales cuya descripción se omite por simplicidad), que proporcionan los puntos de anclaje de cuya tracción por los filamentos finos resulta el acortamiento de las células durante la contracción.

Los filamentos gruesos están formados por múltiples unidades de la proteína de gran tamaño miosina. Cada una de ellas está formada un par de grandes cadenas pesadas, y dos pares de cadenas ligeras, más pequeñas. Cada cadena pesada consta de una porción filamentosa o "cola", que se entrelaza con la otra, y el conjunto se alinea en paralelo con las de otras moléculas de miosina, polimerizándose, para formar el núcleo del filamento grueso. También contiene otra porción globular ("cabeza"), de modo que las cadenas pesadas de la molécula de miosina se asemejan a dos palos de golf entrelazados. Las cabezas globulares se proyectan desde la superficie del filamento formando las estructuras conocidas como puentes cruzados, orientados hacia los filamentos finos, con cuyas moléculas de actina pueden unirse, dadas las circunstancias apropiadas, formando actomiosina. Las cabezas de las cadenas pesadas de la miosina tienen la propiedad esencial 
de poder hidrolizar al ATP liberándose energía (actividad ATP-asa, regulada por su unión a la actina). Ello permite a las cabezas de miosina bascular con un movimiento de vaivén, uniéndose a sucesivas moléculas de actina ("ciclo de los puentes cruzados"), lo que arrastra el filamento fino sobre el grueso produciendo el acortamiento del músculo y el desarrollo de fuerza. Como se señaló arriba, la molécula de miosina también contiene dos pares de pequeñas cadenas ligeras, unidas a las cabezas globulares de las cadenas pesadas, dos son llamadas "esenciales" y otras dos "reguladoras"; estas últimas tienen una importancia crucial en la regulación de la contracción del músculo liso (ver debajo).

En todos los tipos de músculo, liso y estriado, la contracción se inicia al elevarse la concentración de calcio en el citosol $\left[\mathrm{Ca}^{+2}\right] \mathrm{i}$, lo que activa la ATP-asa y el ciclo de los puentes cruzados. En los músculos estriados el calcio ejerce este efecto uniéndose a la proteína de los filamentos finos troponina, suprimiendo la inhibición que ésta ejerce sobre la interacción actina-miosina. El músculo liso carece de troponina y la regulación de la contracción tiene lugar esen- cialmente en los filamentos de miosina, dependiendo del estado de fosforilación de sus cadenas ligeras reguladoras (rMLC, "regulatory myosin light chain"). Sólo cuando éstas se encuentren fosforiladas puede producirse la activación por la actina de la ATP-asa de la cabeza de la cadena pesada de miosina y, por tanto, la contracción muscular.

Las células musculares lisas contienen dos enzimas dedicadas a la regulación de tan crucial fenómeno: una es la cinasa de la cadena ligera de la miosina (MLCK, "myosin light chain kinase"), que fosforila a ésta $y$, por ello determina la contracción del músculo liso. A la anterior se contrapone la actividad de otra enzima, la fosfatasa de la cadena ligera de la miosina (MLCP, "myosin light chain phosphatase"), que defosforila las cadenas ligeras terminando así la contracción. En definitiva, el balance entre las actividades contrapuestas de la MLCK y la MLCP determina el grado de contracción del músculo liso (6). Las señales reguladoras de la contracción y relajación del músculo liso actúan fundamentalmente provocando la activación o la inhibición de las citadas enzimas (Figura 1).

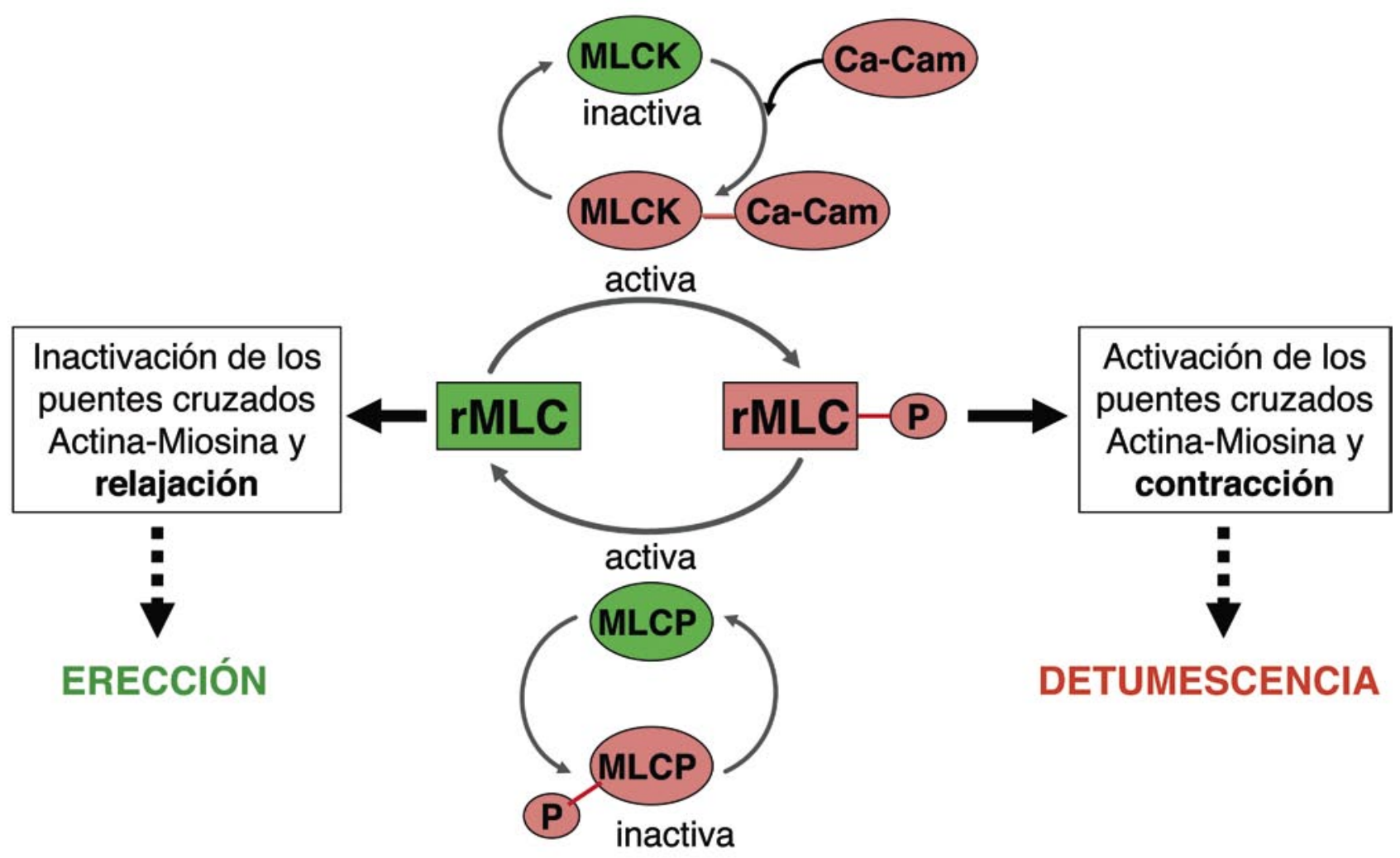

FIGURA 1. Componentes básicos de la regulación del aparato contráctil de las células musculares lisas. El factor clave es el estado de fosforilación de la cadena ligera reguladora de la miosina (rMLC), ya que controla la interacción actina-miosina. Las enzimas y cofactores se representan como elipsoides; las conformaciones o estados de fosforilación procontráctiles en color rojo, los prorelajantes en verde. Ca-Cam: complejo calcio-calmodulina; MLCK: cinasa de la cadena ligera de la miosina; MLCP: fosfatasa de la miosina. 


\section{Mecanismos de señalización en el Músculo Liso Ca- vernoso}

El crucial balance de las actividades MLCK y MLCP viene determinado por la interacción de los efectos de múltiples señales de comunicación intercelular a las que los diversos músculos lisos del organismo, y el cavernoso en particular (1-6) tienen capacidad para responder (Tabla I).

\section{- Señales contráctiles y mecanismos de sensibiliza- ción al calcio}

La MLCK, cuya actividad de fosforilación de la MLC es esencial para la contracción del músculo liso, resulta activada por la unión a ella de la proteína citosólica calmodulina cuando ésta tenga 3 o 4 átomos de calcio ligados (complejo Ca-Cam). Ello ocurre cuando $\left[\mathrm{Ca}^{+2}\right] \mathrm{i}$ se eleve desde el nivel basal de 100 nM hasta 500-700 nM. La unión del complejo Ca-Cam a la MLCK provoca en ésta un cambio conformacional que expone su centro catalítico loculto en el estado inactivo) y le permite fosforilar a la rMLC (Figura 1).

Tal es el efecto, al menos inicial, de los agonistas como el neurotransmisor simpático noradrenalina (NA), péptidos vasoconstrictores como endotelina I o angiotensina II generados por el endotelio o prostanoides vasoconstrictores producidos por el endotelio o las propias células musculares $(1-5,7)$. Algunos de ellos, particularmente la NA liberada por

TABLA I. PRINCIPALES MENSAJEROS INTERCELULARES QUE REGULAN LA ACTIVIDAD CONTRÁCTIL DEL MÚSCULO LISO CAVERNOSO.

\begin{tabular}{|l|l|}
\hline CONSTRICTORES & \multicolumn{1}{|c|}{ RELAJANTES } \\
\hline Noradrenalina (NA) & Óxido Nítrico (NO) \\
\hline Neuropéptido Y & Acetilcolina* \\
\hline Endotelina I & Péptido Intestinal Vasoactivo \\
\hline Angiotensina II & ATP, Adenosina * \\
\hline Prostanoides (PGF2 $\alpha, \ldots)$ & Prostanoides (PGEs, ...) \\
\hline
\end{tabular}

*Indirectamente, induciendo la liberación de NO por el endotelio e inhibiendo la de NA por las terminaciones simpáticas.

* *arecen ejercer efectos directos sobre el músculo liso (receptores P2Y) e indirectos, a través de la liberación de NO por el endotelio. los nervios simpáticos, parecen ejercer fisiológicamente una acción tónica, manteniendo al pene en su estado más habitual de flacidez.

Los referidos agonistas actúan uniéndose a receptores específicos localizados en la membrana de las células musculares lisas, activando en ella la enzima fosfolipasa $C(P L C)$, que produce un aumento de inositol trifosfato (IP3), mensajero intracelular que induce la liberación de $\mathrm{Ca}^{+2}$ desde el refículo endoplásmico al citosol, elevándose $\left[\mathrm{Ca}^{+2}\right] \mathrm{i}$. El complejo Ca-Cam resultante se une a la MLCK activándola como se describió arriba. La MLCK así activada fosforila a la rMLC, con la consiguiente activación del ciclo de los puentes cruzados, la estimulación de la actividad ATPasa de la miosina y la contracción muscular (Figura 2).

Sin embargo, la elevación de $\left[\mathrm{Ca}^{+2}\right] \mathrm{i}$ producida por los agonistas es generalmente transitoria, aunque el estado de contracción puede persistir aún cuando sus niveles hayan descendido al nivel basal. Así, mientras que el arriba descrito mecanismo " $\mathrm{Ca}^{+2}$ - dependiente" parece ser el determinante del inicio de la contracción de las células musculares lisas, en aquellas que mantienen un grado importante de contracción sostenida durante la mayor parte del tiempo, como es el caso del músculo liso vascular en general y muy especialmente el cavernoso, parece operar otro mecanismo por el que se mantiene el estado de contracción aún con niveles bajos de $\left[\mathrm{Ca}^{+2}\right] \mathrm{i}$. Además, los referidos agonistas producen una mayor ratio de fuerza contráctil /[ $\left[\mathrm{Ca}^{+2}\right]$ i que los aumentos de $\left[\mathrm{Ca}^{+2}\right] \mathrm{i}$ inducidos por la mera despolarización de la membrana celular (por ejemplo, con cloruro potásico) (8-9).

Dicho fenómeno refleja el hecho de que la estimulación con NA y otros agonistas adicionalmente pone en marcha un mecanismo llamado de "sensibilización al calcio" que implica la inhibición de la MLCP. Lo hacen activando una proteína reguladora, RhoA que a su vez activa la enzima Rho-cinasa (ROCK), la cual fosforila la MLCP, manteniéndola así en un estado inactivo (10-11). Es de destacar que el músculo liso cavernoso expresa la RhoA en cantidades muy superiores al de otros órganos (12). Además del citado efecto de inactivación directa de la MLCP, la ROCK también activa, mediante su fosforilación, una proteína inhibidora de la MLCP, la CPI-17. Esta proteína es también fosforilada por la protein cinasa $C(P K C)$, enzima activada por el diacilglicerol (DAG) resultante al igual que el IP3 de la actividad de PLC inducida por los agonistas (Figura 2). En definitiva, como consecuencia de la activación de la vía RhoA/ ROCK, la rMLC permanece fosforilada tras el estímulo inicial, aunque la elevación de $\left[\mathrm{Ca}^{+2}\right]$ i haya remiti- 
do. Se mantienen así activados los puentes cruzados y, por tanto, la contracción sostenida de las células musculares lisas, lo que a nivel del cuerpo cavernoso se traduce en el estado de flacidez. Otro mecanismo adicional por el que la ROCK podría contribuir a mantener el estado de contracción es mediante la inactivación, por fosforilación, de la proteína calponina contenida en los filamentos finos que, como se mencionó arriba, parece ejercer una función inhibitoria de la interacción actina-miosina (13). Al aumento anómalo de la actividad de la vía de señalización
RhoA/ROCK se atribuye ahora un papel relevante en la patogenia de diversos trastornos vasculares, como la hipertensión o el vasospasmo (6), así como la disfunción eréctil (10-12). En consecuencia el desarrollo de fármacos que la inhiban motiva actualmente un activo campo de investigación sobre la misma.

\section{- Señales relajantes del músculo liso cavernoso}

La relajación del músculo liso cavernoso, y por tanto el inicio y mantenimiento de la erección del pene, se puede inducir por diversos mensajeros

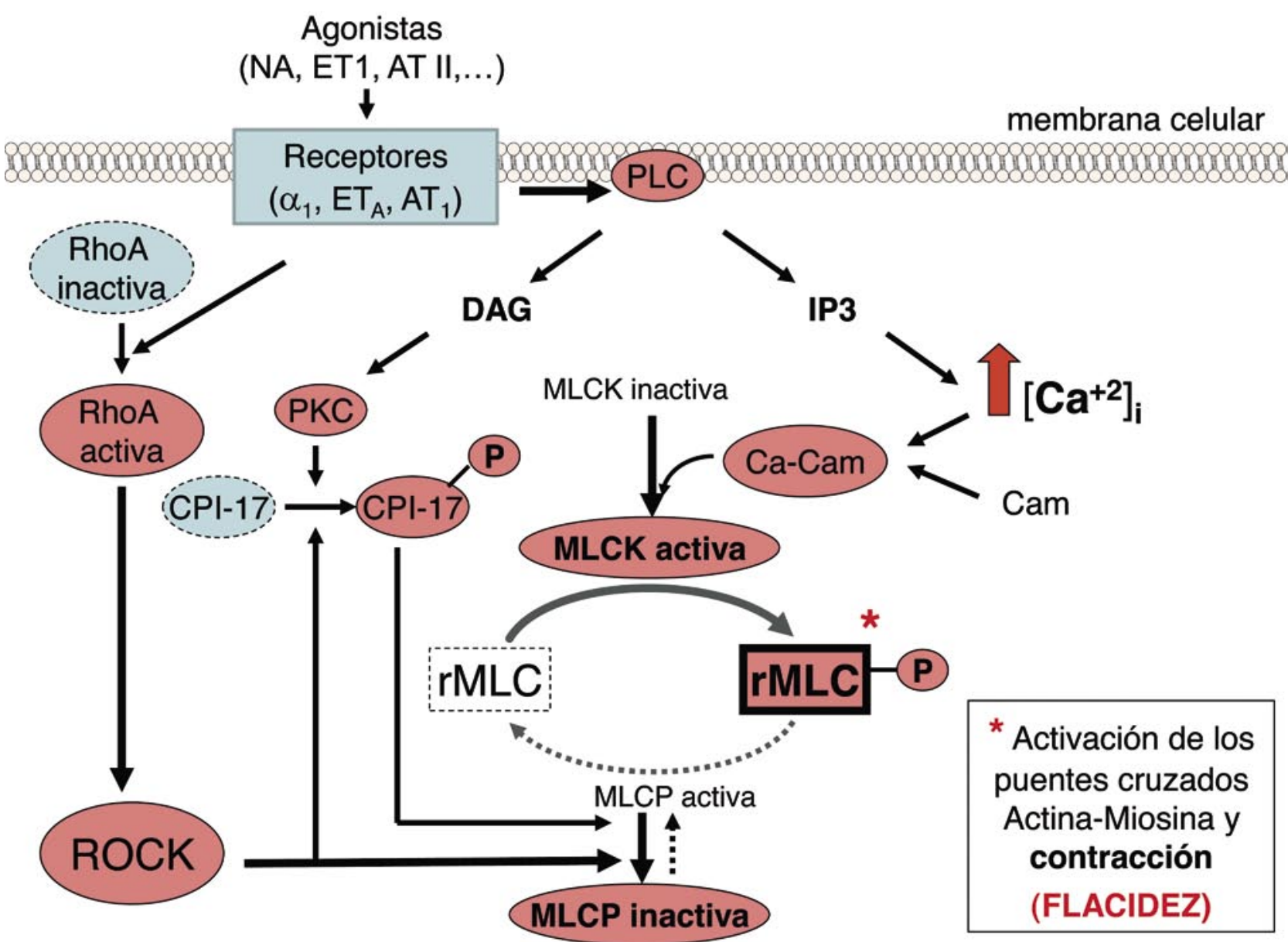

FIGURA 2. Mecanismo de la regulación de la contracción del músculo liso cavernoso inducida por agonistas por las vías (i) dependiente del Ca+2 (derecha) y (ii) de sensibilización al $\mathrm{Ca}^{+2}$ (izquierda). La unión de los agonistas a sus receptores de membrana activa la PLC, que cataliza la formación de IP3 y DAG. (i) IP3 eleva [Ca+2]i al promover su entrada desde el espacio extracelular y su liberación desde el retículo endoplásmico. Al aumentar [Ca $\left.{ }^{+2}\right] i$ la calmodulina (Cam) liga este ión y el complejo resultante (Ca-Cam) se une a la MLCK activándola. Se produce así la fosforilación de la cadena ligera reguladora de la miosina (rMLC) y la activación de los puentes cruzados actina-miosina, iniciándose la contracción del músculo liso. (ii) Paralelamente es activada la proteína reguladora RhoA que, a su vez, activa a la ROCK. Ésta fosforila a la MLCP, lo que la mantiene inactiva. La ROCK también activa, mediante fosforilación, la proteína inhibidora de la MLCP PI-17 que es activada así mismo por la PKG lactivada por DAG). El resultado neto es el mantenimiento de la $\mathrm{rMLC}$ en estado fosforilado (activo), y el músculo liso contraído, aunque $\left[\mathrm{Ca}^{+2}\right]$ i haya descendido a niveles basales. Los receptores y la rMLC se muestran como rectángulos, los enzimas como elipsoides. Las enzimas y configuraciones formas moleculares que promueven la contracción del músculo liso se indican en rojo. 
intercelulares procedentes de diversas fuentes. Así pueden ser liberados por los nervios erectores (parasimpáticos) como el óxido nítrico (NO), el péptido intestinal vasoactivo (VIP) o el ATP. También pueden generarse en el endotelio, como $\mathrm{NO}$ o prostanoides vasodilatadores (como prostaglandinas E1 y E2) (7) (Tabla I). Actúan uniéndose a receptores específicos con diversas localizaciones en las celulares musculares lisas, de lo que resulta la generación de "segundos mensajeros" intracelulares, moléculas que actuando sobre diversos sistemas enzimáticos efectúan la relajación del aparato contráctil (Figura 3).
Hay consenso general en que la vía de señalización de mayor relevancia fisiológica para la iniciación y mantenimiento de la erección peneana es el sistema NO/cGMP/PKG $(1-5,14,16)$.

El NO es generado por la reacción del aminoácido L-arginina con oxígeno molecular, proceso catalizado por una familia de enzimas, las NO sintasas (NOS). Las isoformas presentes en las terminaciones de los nervios erectores (nNOS) y en las células endoteliales (eNOS) son activadas al unirse a ellas el complejo Ca-Cam que es un regulador de múltiples

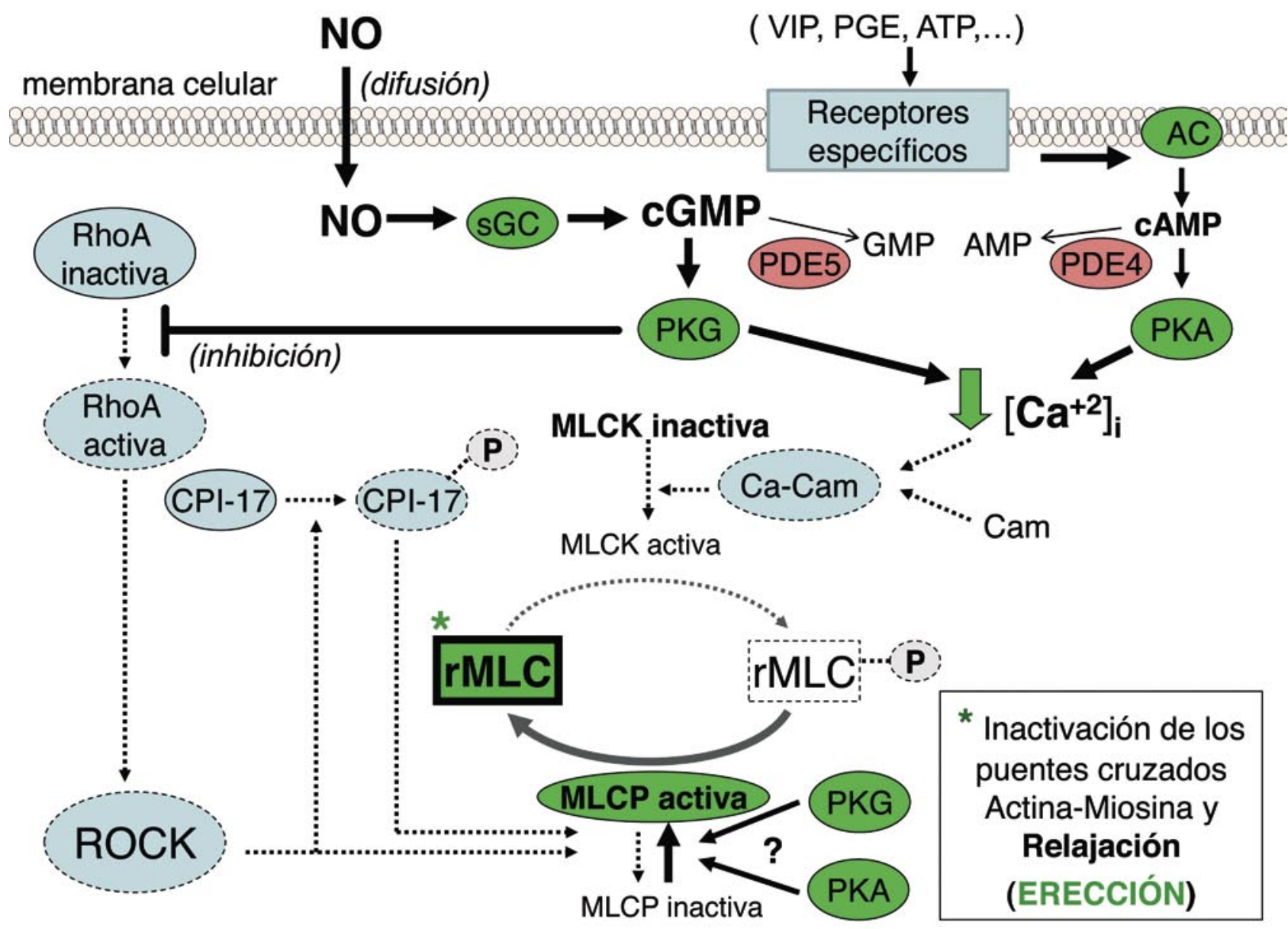

FIGURA 3. Mecanismos moleculares de la relajación del músculo liso cavernoso. La unión de los mediadores intercelulares a sus respectivos receptores /la sCG citosólica para el NO y receptores de membrana asociados a la adenil ciclasa para los otros) lleva a la generación de los nucleótidos cíclicos cGMP y cAMP, que activan a sus respectivas proteín kinasas (PKG y PKA). Éstas fosforilan diversas proteínas, incluídos canales iónicos de la membrana celular y transportadores de $\mathrm{Ca}^{+2}$ hacia el retículo endoplásmico, de lo que reduce los niveles de [C $\mathrm{Ca}^{+2}$ ] y de Ca-Cam. En consecuencia la MLCK deja de ser activada. Paralelamente la PKG desactiva el mecanismo de sensibilización al calcio al inhibir la activación de RhoA, y así la actividad de ROCK, permitiéndose a la MLCP pasar a su forma activa (defosforilada). La MLCP activada defosforila la rMLC, inhibiéndose la actividad contráctil. Aunque menos documentado (símbolo ?), es probable que PKG y PKA también catalicen de modo más directo la defosforilación de la MLCP. Las actividades enzimáticas y estados moleculares que promueven la relajación se muestran en verde, las enzimas que los limitan en rojo. Las vías que resultan activadas se indican en trazo continuo y las que son inhibidas en trazo discontínuo. Véanse los pies de las figuras anteriores para explicación de otros símbolos. 
funciones celulares). Así, la llegada de potenciales de acción a las terminaciones de los nervios erectores produce un aumento de $\left[\mathrm{Ca}^{+2}\right]$ i en las mismas, su unión a calmodulina allí presente y la inmediata activación de la nNOS, generándose $\mathrm{NO}$ que difunde hacia las células musculares lisas iniciando su relajación. Se considera éste el primero de la sucesión de eventos, a nivel del cuerpo cavernoso, que determinan la respuesta eréctil fisiológica. Paralelamente los nervios erectores activados liberan acetilcolina que, actuando sobre receptores muscarínicos en la membrana de las células endoteliales, aumenta en ellas los niveles de $\left[\mathrm{Ca}^{+2}\right]$ i y por ende de $\mathrm{Ca}-\mathrm{Cam}$, que activa la eNOS. El NO así generado por el endotelio

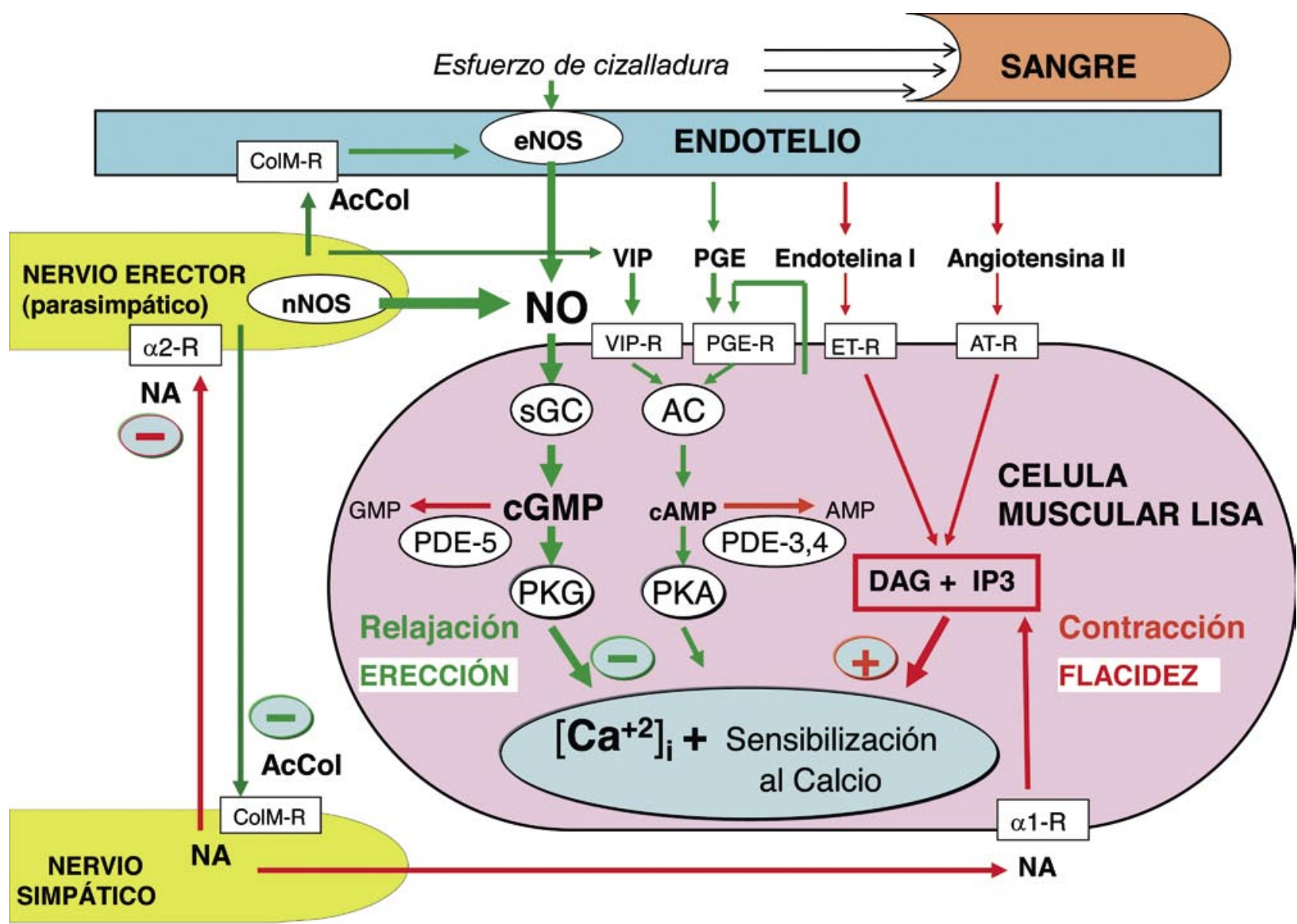

FIGURA 4. Esquema de las principales señales inter-e intracelulares que intervienen en el control de la actividad contráctil del músculo liso cavernoso. En el lado izquierdo de la figura se ha esquematizado la interacción presináptica recíprocamente inhibitoria entre las terminaciones nerviosas parasimpáticos y simpáticas mediante sus neurotransmisores "clásicos" acetilcolina (AcCol ) y noradrenalina (NA). En el estado de vigilia, en ausencia de excitación sexual los órganos eréctiles se encuentran en estado de flacidez, consecuencia del predominio de señales pro-contráctiles que actúan sobre receptores de la membrana de las células musculares, como las esquematizadas a la derecha del diagrama. Entre ellas destacan la acción tónica de las fibras simpáticas (liberando NA) y señales generadas en el propio tejido (como la endotelina); entre todas mantienen el músculo cavernoso contraído probablemente mediante una combinación de mecanismos dependiente del $\mathrm{Ca}^{+2}$ y de sensibilización al $\mathrm{Ca}^{+2}$. La excitación sexual provoca la descarga de $\mathrm{NO}$ por los nervios erectores y su liberación por el endotelio estimulado por la acetilcolina también liberada por aquellos y probablemente por señales mecánicas como el esfuerzo de cizalladura producido por la sangre entrante. El NO ejerce varias acciones sobre las células musculares lisas, que favorecen su relajación. A esta vía NO/sGC/cGMP/PKG se atribuye la mayor importancia para la regulación fisiológica de la erección. La vía CAMP/PKA, activada por mensajeros como el péptido intestinal vasocactivo (VIP) y las prostaglandinas E (PGE), es probable que tenga un papel complementario. Ambos nucleótidos cíclicos son inactivados por diversas fosfodiesterasas (PDE), de distinta especificidad. En el cuerpo cavernoso humano el cGMPc, es inactivado por la PDE5 y el AMPc por las PDE 3 y 4. Los receptores se representan como rectángulos, las enzimas como elipsoides. Las flechas verdes y rojas indican, respectivamente, las vías facilitadoras e inhibidoras de la erección. 
se añade al liberado por las terminaciones nerviosas contribuyendo a mantener la relajación del músculo liso cavernoso, y por tanto la erección, iniciada por aquellas (Figura 4). La actividad de la eNOS es regulada por numerosas señales, además de las nerviosas (7); de especial relevancia parece su activación por el esfuerzo de cizalladura ("shear stress") resultante de la entrada de sangre $y$, probablemente, de los movimientos de fricción del pene.

El NO es un gas muy liposoluble y como tal difunde libremente a través de las membranas celulares hasta el citosol de las células musculares donde encuentra a la enzima guanil ciclasa soluble (sGC), a la que activa para generar guanosín monofosfato cíclico (cGMP), el principal mediador intracelular de las acciones fisiológicas del NO. Los otros mensajeros intercelulares relajantes del músculo liso cavernoso ejercen su efecto uniéndose a receptores acoplados a proteínas $G$ que están localizados en la membrana de dichas células. La unión de sus ligandos específicos se traduce en la activación del enzima adenil ciclasa que genera adenosin monofosfato cíclico (cAMP).

Ambos "segundos mensajeros" ejercen gran parte de sus efectos al unirse, activándolas, a sendas protein cinasas (PK); el cGMP activa la PKG y el cAMP la PKA las cuales, mediante la fosforilación de diversas proteínas "diana", esencialmente enzimas y canales iónicos, llegan a producir la relajación del aparato contráctil de las células musculares lisas (Figura 3).

El mecanismo tradicionalmente aceptado por el que los aumentos de cGMP, o de cAMP, inducen la relajación del músculo liso implica, en último término, el descenso de $\left[\mathrm{Ca}^{+2}\right]$ i, lo que impediría la formación del complejo Ca-Cam necesario para la activación de la MLCK. Sin embargo, como se apuntó en la sección anterior durante la respuesta contráctil producida por agonistas, tras la elevación inicial de $\left[\mathrm{Ca}^{+2}\right] \mathrm{i}$ que inicia la contracción del músculo liso, en la subsecuente fase de mantenimiento $\left[\mathrm{Ca}^{+2}\right] \mathrm{i}$ decrece a niveles similares a los de reposo (8-9). Dicha fase "de mantenimiento" de la contracción es en la que cabe esperar se encuentre el músculo liso cavernoso durante el estado más habitual del pene (flacidez), por lo que parece improbable que el mecanismo de su relajación, para provocar la erección, inducida por el sistema NO/cGMP/PKG (o, en su caso, el cAMP/PKA) se base en la disminución de unos niveles de $\left[\mathrm{Ca}^{+2}\right] \mathrm{i}$ ya de por sí bajos (10). Un mecanismo alternativo propuesto es el que la PKG, activada por el sistema NO/cGMP (y posiblemente también la PKA activada por la vía del cAMP) inhibe al sistema de sensibilización al calcio RhoA/ROCK, lo que previene la inactivación por éste de la MLCP (17) (Figura 3). La relevancia de dicho mecanismo para la erección del pene se corrobora por la respuesta eréctil a la inyección intracavernosa de inhibidores de ROCK documentada en modelos animales $(10-11,18)$. Además del referido mecanismo de inhibición" de la MLCP, se ha propuesto que esta enzima puede ser también directamente activada por la PKG y la PKA, a través de un mecanismo más bien complejo que implica una suerte de "fosforilación competitiva", (19).

La señalización intracelular por parte de los referidos nucleótidos cíclicos se termina por la acción de una serie de enzimas, las fosfodiesterasas (PDEs), que catalizan la hidrólisis del anillo ciclofosfato del cGMP y cAMP resultando los nucleótidos inactivos GMP y AMP respectivamente (20-21). En los mamíferos se han identificado al menos 11 familias codificadas por diferentes genes. Se diferencian unas de otras por su especificidad de sustrato, así unas degradan solamente cGMP (como las PDE 5, 6 y 9), otras cAMP (PDE 4, 7 y 8) y otras ambos (PDE 1, 2, $3,8,9,10$ y 111 , aunque con distintas afinidades 0 eficiencia de la catálisis (por ejemplo, la PDE3 muestra mayor actividad enzimática frente al cAMP que para el cGMP); hay también diferencias en cuanto a su regulación (por los nucleótidos cíclicos o por fosforilación) y en su expresión en distintos tejidos. En los cuerpos cavernosos del pene humano se expresan las PDE 3, 4 y 5; siendo la PDE5 más abundante y de mayor importancia funcional $(22,23)$. Ello es congruente con el concepto ampliamente aceptado de que el principal sistema de regulación fisiológica de la erección del pene en el hombre es la vía de señalización NO/cGMP/PKG regulado por la PDE5 y con la alta eficiencia demostrada por los fármacos orales que inhiben selectivamente esta enzima (PDE5Is) para facilitar la erección peneana en una mayoría de los pacientes aquejados de disfunción eréctil (24).

Las referidas vías de señalización del cGMPc y del cAMP se influyen mutuamente (25-26). Por ejemplo, los PDE5Is no solo elevan los niveles intracelulares cGMP, también aumentan indirectamente los de CAMP al competir aquel por el centro catalítico de la PDE3; a su vez el cAMP puede actuar como un inhibidor competitivo de la PDE5. Por otra parte, en modelos animales, la administración intracavernosa repetida de $P G E 1$, que activa primariamente la vía del CAMP (Figura 4), induce un aumento de los enzimas productoras de $\mathrm{NO}$ en los nervios erectores y el endotelio así como de las respuestas eréctiles y de liberación de NO tras la estimulación de aquellos (27). Tal fenómeno implicaría una amplificación de la vía del GMPc, por lo que cabe esperar aumente el efecto de los PDE5Is. En consonancia con ello en muchos pacientes no respondedores inicialmente al 
tratamiento con PDE5Is, una breve serie de inyecciones intracavernosas pautadas de PGE 1 permite que respondan ulteriormente a los PDE5Is orales tomados a demanda, incluso a dosis menores a las que antes se habían mostrado inefectivas (28).

\section{CONCLUSIÓN}

Los estados fisiológicos de flacidez o de erección del pene resultan de la interacción de diversas vías de señalización molecular, inter- e intracelulares, que promueven la contracción o la relajación de las células musculares lisas del cuerpo cavernoso resumidas en la Figura 4.

En el estado de flacidez, más frecuente, hay una actividad tónica de la inervación simpática con liberación de NA que, además de mantener inhibidos los nervios erectores a través de receptores presinápticos a2, genera señales contráctiles en el músculo liso cavernoso, con la cooperación probable de señales vasoconstrictoras procedentes del endotelio. Todas ellas actúan sobre receptores de membrana de las células musculares lisas que activan la PLC con la generación de los mensajeros intracelulares IP3 y DAG. El resultado es un aumento transitorio de $\left[\mathrm{Ca}^{+2}\right] \mathrm{i}$ que inicia la respuesta contráctil y la activación paralela del mecanismo de "sensibilización al calcio" operado por la vía RhoA/ROCK, que la mantiene. Una sobre-expresión de ésta parece contribuir a la patogenia de diversos trastornos vasculares como la hipertensión, el vasoespasmo o la disfunción eréctil.

La estimulación sexual se traduce en potenciales de acción en los nervios erectores, activándose su nNOS y generando $\mathrm{NO}$ que inicia la respuesta eréctil; la liberación concomitante de acetilcolina, además de inhibir presinápticamente la liberación de NA en los nervios simpáticos, activa la eNOS del endotelio, probablemente con la contribución de otras señales como el esfuerzo de cizalladura, y el NO producido por ésta se suma al de origen neural. La entrada de NO por difusión a las células musculares lisas genera en ella cGMP que, activando la PKG, produce en ellas una serie de reacciones que llevan a la disminución de $\left[\mathrm{Ca}^{+2}\right]$ i y la inactivación del mecanismo de sensibilización al calcio y consecuentemente a la relajación del músculo liso cavernoso. A este sistema principal de señalización erectogénica se añade, con efectos similares, el formado por la vía cAMP/PKA, activada por diversos mensajeros intercelulares de origen neural y paracrino. La acción de dichos nucleótidos cíclicos se termina cuando son inactivados por las PDEs. La inhibición farmacológica de estas enzimas, particularmente la PDE5 (específica del cGMP), facilita considerablemente la respuesta eréctil. Los mecanismos de intercomunicación existentes entre las diversas vías de señalización erectogénicas (cGMP y cAMP) pueden también aprovecharse en la terapia farmacológica de la disfunción eréctil.

Es de esperar que la presente descripción, aunque muy simplificada en aras de la claridad, ayude a una mejor comprensión de los mecanismos moleculares que producen los estados de flacidez y erección del pene, sus alteraciones en diversas patologías y las posibilidades que ofrecen de intervención terapéutica.

\section{BIBLIOGRAFIA y LECTURAS RECOMENDADAS ( ${ }^{*}$ lectura de interés $y^{* *}$ lectura fundamental)}

**1. Sáenz de Tejada I, Angulo J, Cellek S, GonzálezCadavid N, Heaton J, Pickard R, et al. Physiology of erectile function. J Sex Med 2004; 1: 254-65.

2. Simonsen U, García-Sacristán A, Prieto D. Penile arteries and erection. J Vasc Res, 2002; 39: 283303.

3. Andersson K-E. Erectile physiological and pathophysiological pathways involved in erectile dysfunction. J Urol 2003; 170: S6-S14.

*4. Dean RC, Lue TF. Physiology of penile erection and pathophysiology of erectile dysfunction. Urol Clin North Am 2005 ; 32: 379-395.

*5. 5. Mas M. Fisiología sexual. Tresguerres JAF ed. Fisiología Humana $4^{\mathrm{a}}$ Ed, pp.1172- 83, Madrid: McGraw Hill-Interamericana, 2010.

**6. Watras JM: "Músculo liso". Koeppen BM, Stanton BA eds. Berne y Levy Fisiología, $6^{\mathrm{a}} \mathrm{Ed}$, pp. 268-85, Barcelona: Elsevier España; 2009.

*7. Mas M. A close look at the endothelium: Its role in the regulation of vasomotor tone. Eur Urol Suppl 2009; 8: 48-57.

8. Hirano K. Current topics in the regulatory mechanism underlying the $\mathrm{Ca} 2+$ sensitization of the contractile apparatus in vascular smooth muscle. J Pharmacol Sci 2007; 104: 109-15.

9. Karaki H. The intracellular calcium-force relationship in vascular smooth muscle. Time- and stimulus-dependent dissociation. Am J Hypertens 1990; 3 (Pt 2): 253S-256S.

10. Chitaley K, Webb RC, Mills TM. The ups and downs of Rho-kinase and penile erection: upstream regulators and downstream substrates of rho-kinase and their potential role in the erectile response. Int J Impot Res 2003; 15: 105-9.

**11. Jin L, Burnett AL. RhoA/Rho-kinase in erectile tissue: mechanisms of disease and therapeutic insights. Clin Sci 2006; 110: 153-165.

12. Wang H, Eto M, Steers WD, Somlyo AP, Somlyo AV. RhoA-mediated $\mathrm{Ca}^{2+}$ sensitization in erectile function. J Biol Chem 2002; 277: 30614- 21. 
13. Kaneko T, Amano M, Maeda A, Goto H, Takahashi $\mathrm{K}$, Ito $\mathrm{M}$, et al. Identification of calponin as a novel substrate of Rho-kinase. Biochem Biophys Res Commun 2000; 273: 110-6.

*14. Ghalayini IF. Nitric oxide-cyclic GMP pathway with some emphasis on cavernosal contractility. Int J Impot Res 2004; 16: 459-69.

15. Gur S, Hellstrom WJG. Activation of P2Y1 and P2Y2 nucleotide receptors by adenosine 5_-triphosphate analogues augmented nerve-mediated relaxation of human corpus cavernosum. Can Urol Assoc J 2009; 3: 314-8.

**16. Lin C-S, Lin G, Lue TF. Cyclic nucleotide signaling in cavernous smooth muscle. J Sex Med 2005; 2: 478-91.

17. Sauzeau V, Le Jeune H, Cario-Toumaniantz C, Smolenski A, Lohmann SM, Bertoglio J, et al. Cyclic GMP-dependent protein kinase signaling pathway inhibits RhoA-induced $\mathrm{Ca}^{2+}$ sensitization of contraction in vascular smooth muscle. J Biol Chem 2000; 275: 21722-9.

18. Chitaley K, Webb RC, Mills TM. RhoA/Rho-kinase: a novel player in the regulation of penile erection. Int J Impot Res 2001; 13:67-72.

19. Ito M, Nakano T, Erdodi F, Hartshorne DJ. Myosin phosphatase: structure, regulation and function. Mol Cell Biochem 2004; 259:197-209.

20. 20. Corbin JD. Mechanisms of action of PDE5 inhibition in erectile dysfunction. Int J Impot Res 2004; 16 (Suppl 1): S4-S7.

*21. Lin C-S. Phosphodiesterase type 5 regulation in the penile corpora cavernosa. J Sex Med 2009; 6(suppl 3): 203-9.

22. Oelke M, Hedlund P, Albrecht K, Ellinghaus P,
Stief CG, Jonas U, et al. Expression of cAMP and cGMP-phosphodiesterase isoenzymes 3, 4, and 5 in the human clitoris: immunohistochemical and molecular biology study. Urology 2006; 67: 1111-6.

23. Waldkirch E, Uckert S, Yildirim H, Sohn M, Jonas U, Stief CG, et al. Cyclic AMP-specific and cyclic GMP-specific phosphodiesterase isoenzymes in human cavernous arteries- immunohistochemical distribution and functional significance. World J Urol 2005; 23: 405-10.

**24. Francis SH, Morris GZ, Corbin JD. Molecular mechanisms that could contribute to prolonged effectiveness of PDE5 inhibitors to improve erectile function. Int J Impot Res 2008; 20: 333-42.

25. Uckert S, Hedlund P, Waldkirch E, Sohn M, Jonas $\mathrm{U}$, Andersson $\mathrm{KE}$ et al. Interactions between cGMP- and cAMP-pathways are involved in the regulation of penile smooth muscle tone. World $\mathbf{J}$ Urol 2004; 22: 261-6.

26. Kim NN, Huang Y, Moreland RB, Kwak SS, Goldstein I, Traish A. Cross-regulation of intracellular intracellular cGMP and cAMP in cultured human corpus cavernosum smooth muscle cells. Mol Cell Biol Res Commun 2000; 4:10-4.

27. Escrig A, Marín R, Mas M. Repeated PGE1 treatment enhances nitric oxide and erection responses to nerve stimulation in the rat penis by upregulating constitutive NOS isoforms. J Urol 1999;162: 2205-10.

28. Gutiérrez P, Hernández P, Mas M. Combining programmed intracavernous PGE1 injections and sildenafil on demand to salvage sildenafil non-responders. Int J Impot Res 2005; 17: 354-8. 